\title{
Effect of vitamin D supplementation on disease activity (SLEDAI) and fatigue in Systemic Lupus Erythematosus patients with hipovitamin D: An Open Clinical Trial
}

\author{
Achmad Rifa'i', Handono Kalim¹, Kusworini², C. Singgih Wahono ${ }^{1}$
}

\begin{abstract}
'Division of Rheumatology and ImmunologyDepartment of Internal Medicine, University of Brawijaya / dr.Saiful Anwar Hospital Malang 2Department of Clinical Pathology,University of Brawijaya/dr.Saiful Anwa Malang
\end{abstract}

\section{Corespondence :}

Achmad Rifa'i, MD

Division of Rheumatology and ImmunologyDepartment of Internal Medicine

University of Brawijaya / dr.Saiful Anwar Hospital Malang, dwirifai76@yahoo.co.id,

\begin{abstract}
Background : Low level of vitamin D impact the disease activity and the degree of fatigue in SLE patients. This study aims to determine the effect of vitamin $D$ supplementation on disease activity and fatigue condition in Systemic Lupus Erythematosus (SLE) patients with hipovitamin D.

Methods: We performed an open clinical trial. Subjects were randomized into two different groups (supplementation or placebo) using simple random sampling. The treatment group got vitamin D3 softgel/ cholecalciferol $1200 \mathrm{IU} /$ day or $30 \mathrm{mg} /$ day, while the control group gotplacebo for 3 months. SLEDAI scores and FSS scores were calculated at pre and post treatment.

Results: There were 20 subjectsfor supplementation group and 19 subjects in the placebo group. From this study, before and after treatment, we found a significant difference of mean level of vitamin $D$ in supplementation group $(p=0.000)$, and no significant difference in patients with placebo $(p=0.427)$. Moreover, from the SLEDAI score analysis, observed a significant difference bothin the supplemented group $(p=0.000)$ and the placebo group $(p=0.006)$. FSS scores significantly different in the supplemented group $(p=0.000)$. In correlation test, there was a negative correlation $(r=-$ 0763) between vitamin D level and disease activity (SLEDAI), and both showing stastistical significance between thepre supplementation $(p=0.000)$ and post supplementation $(r=-0846 ; p=0.000)$. Similarly to the FSS scores, there was a meaningfulnegative correlation $(r=-0.931, p=0.000)$ between the level of vitamin $D$ with FSS scores pre and post supplementation $(r=-0.911 ; p=0.000)$. Furthermore, there was a significant correlation between disease activity (SLEDAl) pre supplementation with fatigue condition pre supplementation $(r=0.846 ; p=0.000)$ and post supplementation $(r=0.913 ; p=0.000)$.
\end{abstract}

Conclusion: The supplementation of vitamin D $1200 \mathrm{IU}$ per day in patients with SLE improve disease activity and degree of fatigue.

Keywords: vitamin D, disease activity, fatigue, SLE

\section{Background}

Systemic Lupus Erythematosus (SLE) is a chronic autoimmune disease that affects almost every organ in human body. This disease primarily affects women in reproductive age with the female: male ratio 8: 1. Prevalence of SLE has been reportedto be 12.2 per 100,000 population with a high mortality and morbidity rate, especially in developing countries. Although 5 years survival rate of patients SLE has increased to $90 \%$ at developing countries, but Handono, et al. (2000) showed that SLE patients in Indonesia hadlower life expectancy,with only $70 \%$ for 5 years survival rate and $50 \%$ for 10 years survival rate. ${ }^{1}$

SLE interferes the autoregulation of the immune system. The role of immune regulation in SLE patients is influenced by the level of vitamin $\mathrm{D},{ }^{2}$ it was supported by the results of a study, which found anegative correlation between vitamin D level and disease activity, degree of fatigue, and production of autoantibody. ${ }^{3}$ Another study conducted in Indonesia stated that $71 \%$ SLEpatients experienced deficiency of vitamin $\mathrm{D}^{4}{ }^{4}$ This low level of vitamin D may be happened due tosun avoidance because of photosensitivity that result inless sun exposure. ${ }^{5}$ Low levelof vitamin $\mathrm{D}$ in patients with SLEhasimpacted the clinical condition of the patient, which would certainly affect the disease activity itself.

Fatigue is a serious problem in SLE patients. One study showed that nearly $81 \%$ of SLEpatients experienced fatigue, $60 \%$ of them had lowsleeping quality. ${ }^{6}$ These results were supported by in vivo studies in SLE patients which proved that the administration of $1,25(\mathrm{OH})_{2} \mathrm{D}_{3}$ improved the life ofquality of patients, and one of it wasfatique ${ }^{7}$. The presence of fatigue in patients with SLE will lower patients' compliance onthe treatment, and causing negative impact on their social life infamily and community. Therefore, this study is aimed to determine the effect of vitamin D supplementation on the disease activity and fatigue condition in SLE patients with hypovitaminosis $\mathrm{D}$.

\section{Research Methods \\ Study Design}

This was an open label clinical trial with a control (SLE patients that get standard SLE therapeutic and plasebo) to assess the effects of vitamin D supplementation on disease activity and the degree of fatigue in SLE patients with hypovitaminosis D. The study was conducted atoutpatient and 
inpatient settingsin Rheumatology division of the Department of Internal Medicine Dr. Saiful Anwar Hospital Malang. Research was carried out from January 2013 to December 2013. The study lasted for 3 months for eachpatient.

\section{Population and Sample Research}

Population in this study was SLE patients who sought treatment from Internal Medicine Deparment Dr Saiful Anwar Hospital within 1 year. Diagnosis was taken based on the ACR criteria 1997. Samples were SLE patients who had vitamin D deficiency and met the inclusion criteria based on the determined time. The subjects were randomized into 2 different groups (group supplementation or placebo) using simple random sampling.

Inclusion and control criterias were: women with SLE, aged 18-43 years old, duration of disease $\leq 1$ year, SLEDAI scores $\geq 5$, experienced hypovitaminosis $\mathrm{D}$, and did not taking any medicationcontaining vitamin $\mathrm{D}$ (diet containing vitamin D was not counted as vitamin D supplementation). The exclusion criterias were: patients suffered severe infection (sepsis), trauma, liver disease with AST and ALT 2.5 above normal, renal disease with GFR $\leq 60$ (cockrofgault), oliguria $<400 \mathrm{cc} /$ day, pregnancy, and breastfeeding.

This study was approved by the Ethics Committee of the Faculty Medicine of Brawijaya University/Dr. Saiful Anwar Hospital. Informed concent has been obtained from all subjects.

\section{Recruitment Procedures Samples}

Patients who met the inclusion and exclusion citerias, and agreed to participate were asked to sign the informed consent, had initial examination and physical examination. SLEDAI scores and FSS score were also evaluated. Then the research subjects were supplemented with vitamin D3 softgel/ cholecalciferol $1200 \mathrm{IU} /$ day or $30 \mathrm{mg} /$ day while the controls were given a placebo.

During the study, patients were routinely followed up in Rheumatology Clinic every Monday or Wednesday to monitor the side effects of Vitamin D supplementation and taking the next month medication. Supervision of drug consumption were done by the patients and their family members who were willing to supervise the patient the early days to count the number of remaining medicine, in order to measure the amount of medicine that had been taken. The monitoring was carried out for 3 months. Monitoring of SLEDAI score, FSS score as well as vitamin D levels was repeated in the end of the study to each sample.

\section{Statistical Analysis}

The differences of vitamin $\mathrm{D}$ levels before and after supplementation of vitamin D were analyzed using pairedsample t-test, $\mathrm{p}<0.05$ was considered significant. In addition,the relationship of disease activity and fatigue conditions were analyzed using Pearson correlation test, and the statistical analysis was performed using SPSS for Windows 17.

\section{Result}

Characteristics of Research Subjects

The number of patients who met the inclusion criteria and exclusion criteria were 20 subjects for treatment groupand 19 people for placebo group. Characteristics of the patients in this study are presented in Table 1.

Table 1. Characteristics of Subjects

\begin{tabular}{llll}
\hline Characteristic & $\begin{array}{l}\text { Supplementation } \\
\text { mean } \pm \text { SD }\end{array}$ & $\begin{array}{l}\text { Placebo } \\
\text { mean } \pm \text { SD }\end{array}$ & $P$ \\
\hline Age (year) & $28.25 \pm 6.97$ & $27.26 \pm 6.76$ & 0.55 \\
Duration of illness (month) & $3.55 \pm 1.90$ & $2.74 \pm 1.86$ & 0.17 \\
Level of Vitamin D (ng/ml) & $23.89 \pm 3.07$ & $26.06 \pm 3.71$ & 0.86 \\
SLEDAl & $12.65 \pm 4.85$ & $10.74 \pm 2.75$ & 0.19 \\
Fatigue Severity Score (FSS) & $5.41 \pm 1.02$ & $4.86 \pm 0.77$ & 0.12 \\
Level of ds DNA & $226.8 \pm 82.1$ & $238.3 \pm 65.0$ & 0.68 \\
Level of Calsium (mg/dl) & $8.85 \pm 0.393$ & $0.898 \pm 0.384$ & 0.322 \\
Early Manifestations(\%) & & & \\
- Mucocutaneous & $6(30 \%)$ & $9(47 \%)$ & \\
- Arthritis & $5(25 \%)$ & $5(26 \%)$ & \\
- Nephritis & $8(40 \%)$ & $4(21 \%)$ & \\
- Haematology disorder & $7(35 \%)$ & $8(42 \%)$ & \\
- Serositis & $3(15 \%)$ & $2(11 \%)$ & \\
- Cerebral & $1(5 \%)$ & $0(0 \%)$ & \\
Treatment (\%) & & & \\
- non immunosupressant & $2(10 \%)$ & $3(15.8 \%)$ & \\
- Azathioprin & $5(25 \%)$ & $5(26.3 \%)$ & \\
- Cyclophosphamid & $2(10 \%)$ & $1(5.30 \%)$ & \\
- Methyl Mecofenolat & $6(30 \%)$ & $3(15.8 \%)$ & \\
- (MMF) & & & \\
\hline
\end{tabular}

\section{Vitamin D Level}

The difference levelof vitamin $\mathrm{D}$ before and after supplementation in control and intervention groups are presented in Figure 1.

Figure 1 Comparison level of vitamin D pre and post supplementation.

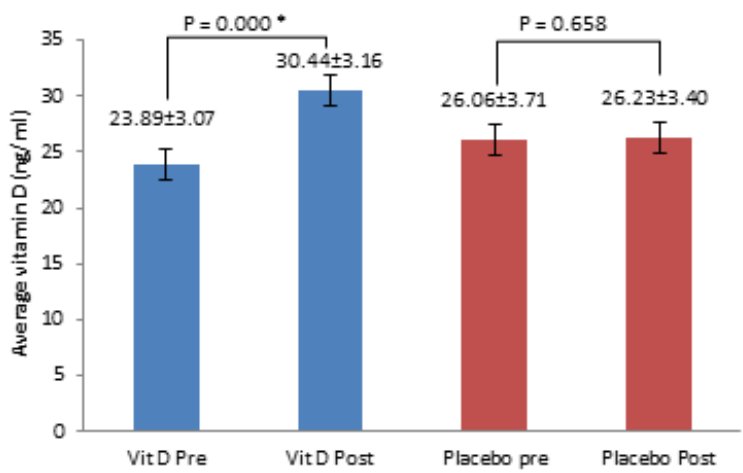

Oral vitamin D supplementation significantly increase the vitamin $\mathrm{D}$ level in intervention group, as shown above. There was significant difference of vitamin D level between pre and post vitamin D supplementation in SLEpatients $(p=0.000)$. While in group of patients with placebo, there was no significant difference between pre and post placebo administration $(p=0.658)$. The mean of delta vitamin $\mathrm{D}$ level before and after intervention were $6.55 \pm 0.09 \mathrm{ng} / \mathrm{ml}$ in experimental group and only $0.17 \pm 1.63 \mathrm{ng} / \mathrm{ml}$ in control group. 


\section{SLEDAI Score}

This study showed that SLEDAI score before and after supplementation had a significant difference, in both group receiving oral vitamin $\mathrm{D}$ and oral placebo. The experimental group showed a decrease in the average value of SLEDAI from $12.65 \pm 4.85$ to $6.20 \pm 2.67$ with a mean decreased $6.45 \pm$ 2.18. Whereas, the placebo group showed a decrease average value of SLEDAI from $10.74 \pm 2.75$ to $9.68 \pm 2.26$ with the mean of decrease $1.06 \pm 0.49$.

Figure 2 Comparison of the decreased SLEDAI score in patients post supplementation versus pre supplementation.

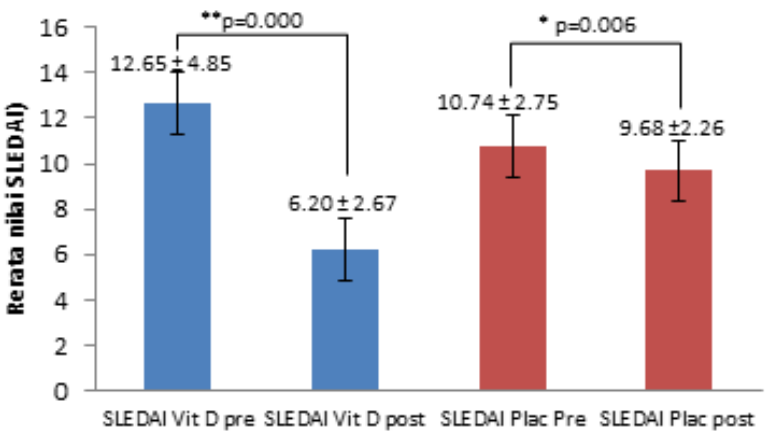

The SLEDAI score in post supplementation was lower than pre supplementation group $(\mathrm{p}=0.000)$. Same as supplementation group, SLEDAI score in post placebo tend to be lower than pre placebo group $(\mathrm{p}=0.006)$.

There was a significant decrease of SLEDAI score in both groups after 3 months trial.

\section{FSS value changes before and after supplementation}

This study showed that FSS score before and after supplementation had a difference, both in the vitamin D supplementation and the placebo group. Vitamin D supplementation group showed a significant decreasing of the average value of FSS score with the mean decrease was 2.25 \pm 0.73 . It means there was a fatigue improvements in group of SLE patients receiving oral vitamin D supplementation. In the placebo group, the decrease was just slightly, with average decrease value only $-0.005 \pm 0.62$, and no statistical difference $(p>0.05)$ were found. The FSS score before and after oral vitamin D supplementation can be seen in Figure 3.

Figure 3 Comparison of FSS score pre and post supplementation.

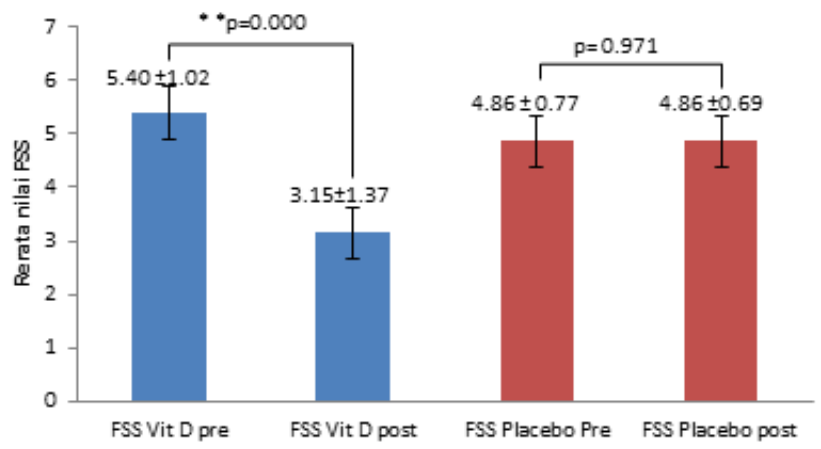

There was a significant difference between the mean FSS score pre and post vitamin D supplementation in SLE patients $(p=0.000)$. While the average FSS score between patients pre and post placebo in SLE patients showed no significant difference $(p=0.971)$.

The significant improvements were seen in all aspect of FSS questions. The higher significant changes $(p<0.001)$ were seenin: fatigue affects motivation (P-1), physical exercise as fatigue precipitator ( $\mathrm{P}-2)$, easy experience of fatigue (P-3), patients often have problems with fatigue (P-5), fatigue affects the physical endurance (P-6), and fatigue as one of the main complained (P-8). While the physical activity disorder ( $\mathrm{P}-4)$, the fatigue affects the duties and responsibilities of the patient (P-7), and the fatigue effect on the environment, family life and social life (P-9) have $\mathrm{p}$ value $<0.05$. Those result shown at Table 2 .

Table 2 The Result of Various Parameters in FSS Score

\begin{tabular}{|c|c|c|c|}
\hline Item & $\begin{array}{l}\text { Pre Supple- } \\
\text { mentation } \\
\text { Mean } \pm \text { SD }\end{array}$ & $\begin{array}{l}\text { Post Supple- } \\
\text { mentation } \\
\text { Mean } \pm \text { SD }\end{array}$ & $\mathbf{P}$ \\
\hline Effect on Motivation (P-1) & $5.00 \pm 1.12$ & $2.95 \pm 1.23$ & .000 \\
\hline $\begin{array}{l}\text { Physical exercise as fatigue } \\
\text { precipitator ( P-2) }\end{array}$ & $4.95 \pm 1.19$ & $3.20 \pm 1.47$ & .000 \\
\hline Easy experience of fatigue (P-3) & $5.30 \pm 1.26$ & $3.20 \pm 1.51$ & .000 \\
\hline $\begin{array}{l}\text { Physical activity disorder } \\
\text { (P-4) }\end{array}$ & $5.45 \pm 1.15$ & $3.10 \pm 1.33$ & .011 \\
\hline $\begin{array}{l}\text { Patients often have problems } \\
\text { with fatigue (P-5) }\end{array}$ & $5.70 \pm 1.26$ & $3.15 \pm 1.42$ & .000 \\
\hline $\begin{array}{l}\text { Fatigue affects the physical } \\
\text { endurance (P-6) }\end{array}$ & $5.40 \pm 1.43$ & $3.25 \pm 1.48$ & .000 \\
\hline $\begin{array}{l}\text { Fatigue affects the duties and } \\
\text { responsibilities of the patient } \\
\text { (P-7) }\end{array}$ & $5.70 \pm 1.03$ & $3.25 \pm 1.52$ & .001 \\
\hline $\begin{array}{l}\text { Fatigue as one of the main } \\
\text { complained (P-8) }\end{array}$ & $5.60 \pm 1.05$ & $3.25 \pm 1.48$ & .000 \\
\hline $\begin{array}{l}\text { Fatigue effect on the enviroment, } \\
\text { family life and social life (P-9) }\end{array}$ & $5.85 \pm 1.27$ & $3.15 \pm 1.42$ & .003 \\
\hline
\end{tabular}

Significant if $p<0.05$

\section{Correlation of vitamin D level with various parameters}

The correlation of disease activity (SLEDAI) between the supplemented group and the placebo group analyzed by Pearson's correlation test. The aim of correlation test was to determine the relationship between disease activity with vitamin D level before and after treatment.

Figure 4 Correlation between level of vitamin D and SLEDAI Score
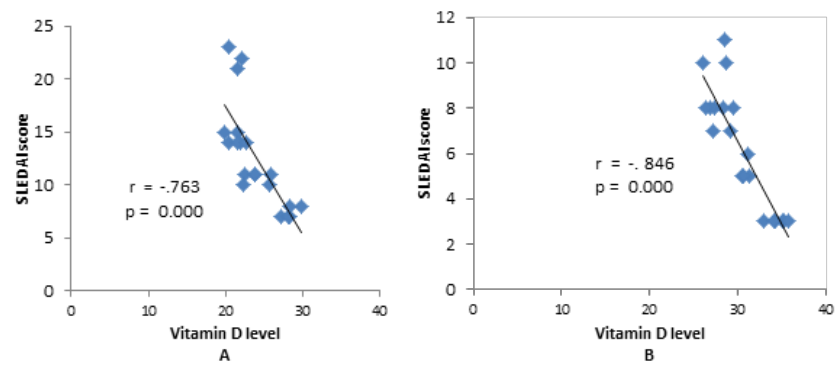

A. Before Vitamin D supplementation; B. After Vitamin D suplementation 
Correlation test showed an inverse relationship between vitamin D level and disease activity (SLEDAI) before supplementation $(\mathrm{p}=0.000 ; \mathrm{r}=-0.763)$. There was a strong relationship between vitamin $\mathrm{D}$ level and disease activity (SLEDAI) after supplementation $p=-0.846$. Negative values indicated an inverse relationship, means when the level of vitamin $\mathrm{D}$ escalates there will be a decrease in disease activity (SLEDAI) .

\section{Figure $\mathbf{5}$ Correlation between level of vitamin D and FSS score}

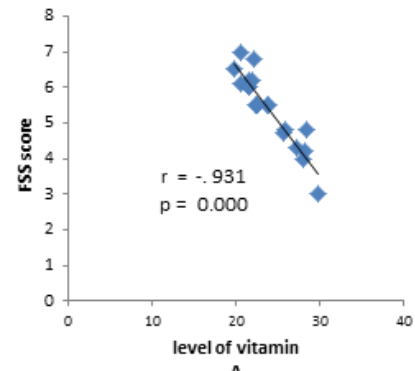

A

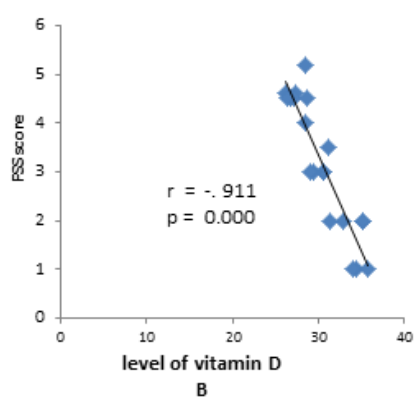

B
A. Before Vitamin D supplementation; B. After Vitamin D suplementation

This study showed association between vitamin D level with the Fatigue Severity Scale (FSS), before and after the supplementation. There was an inverse relationship between vitamin D level with FSS before supplementation ( $\mathrm{p}=0.000$; $\mathrm{r}=-0.931$ ), and also vitamin D levels with FSS after supplementation $(\mathrm{p}=0.000 ; \mathrm{r}=-0.911)$.

Figure 6 Correlation between SLEDAI score and FSS Score
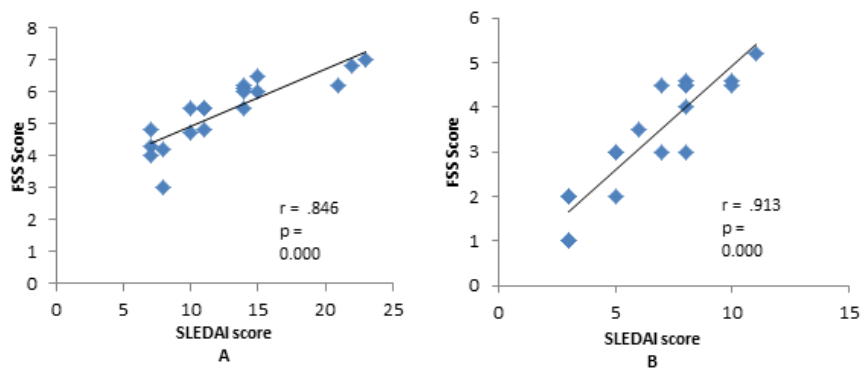

\section{A. Before Vitamin D supplementation; B. After Vitamin D supplementation}

Correlation analysis showed a strong relationship between disease activity (SLEDAI) and fatigue condition before getting supplementation $(\mathrm{p}=0.000 ; \mathrm{r}=0.846)$. There was also strong a relationship between SLEDAI score with FSS after supplementation $(\mathrm{p}=0.000, \mathrm{r}=0.913)$.

\section{Discussion}

Supplementation of cholecalciferol 1200 IU for 3 months gave a positive effect on the increasing levels of $25(\mathrm{OH}) \mathrm{D}$ serum. This showed by significant elevation levels of $25(\mathrm{OH}) \mathrm{D}$ in the supplemented group, with average rise $6.55 \pm 1.27 \mathrm{ng} / \mathrm{ml}$ from the initial baseline. The increasing levels of $25(\mathrm{OH}) \mathrm{D}$ serum slightly lower than the previous study, which resulted an increase vitamin D level approximately $10 \mathrm{ng} / \mathrm{ml}$ with cholecalciferol 1000 IU per day for 3-4 months. Moreover, another study reported an increase level of $25(\mathrm{OH}) \mathrm{D}$ to $40 \mathrm{ng} /$ $\mathrm{ml}$ with 3000IU supplementation of cholecalciferol for three months. ${ }^{9}$ However, the change of $25(\mathrm{OH}) \mathrm{D}$ level does not always have linear correlation with the supplementation of vitamin $\mathrm{D}$, which mean the same dose supplementation of vitamin $\mathrm{D}$ does not always increase the same value of $25(\mathrm{OH})$ $\mathrm{D}$ level in the blood. It is really depend on each individual characteristic. ${ }^{9}$ Similar condition also occured in study conducted by Irastorza, where the elevated levels of $25(\mathrm{OH})$ $\mathrm{D}$ ranged from $3.1 \mathrm{ng} / \mathrm{ml}$, with a median dose of $600 \mathrm{IU}$ (dose range of 400-1200 IU per day). ${ }^{7}$

Patients with SLE often develop photosensitivity, malar rash, and discoid rash on his limbs. Therefore, there is a tendency for SLE patients to avoid sunlight and use photoprotection. ${ }^{10}$ Some literature stated that in healthy condition, accidental sun exposure in the face and hands is "enough" for fulfilling the vitamin D requirement ranging from 5-10 mg (200-400 IU) of vitamin D. Whereas exposure on $5 \%$ skin will produce average $35 \mathrm{nmol} / \mathrm{L} 25(\mathrm{OH}) \mathrm{D}$. Contribution of sunlight to produce vitamin D in the SLE patient is relatively low, and would even be lower if they used sunscreen necessarily. A sunscreen with an SPF of 15 will absorb $99 \%$ of UVB radiation, and, thus, when sunscreen is applied, it will reduce $99 \%$ the synthesis of vitamin D3 in the skin. ${ }^{11,12}$ In addition, the presence of renal insufficiency, caused by chronic use of hidrokloroquin and glucocorticoids in SLE patients can also interfere the metabolism of vitamin D. ${ }^{10}$

Target levels of 25(OH)D in SLE patients is $30 \mathrm{ng} / \mathrm{ml}$. In this level, the risk of morbidity caused by hypovitaminosis D will be greatly reduced. In this study, we found that giving 3 month oral vitamin D supplementation would result the $50 \%$ of patients achieved the target level with $25(\mathrm{OH}) \mathrm{D}$ value greater than or equal to $30 \mathrm{ng} / \mathrm{ml}$. There is no evidence of additional benefits in $25(\mathrm{OH}) \mathrm{D}$ levels more than $40 \mathrm{ng} / \mathrm{ml} .{ }^{13}$

In this study, there was an inverse relationship between SLEDAI and FSS score with vitamin D level in both groups. However, the result of supplementation group greater than the placebo group with a strong correlation coefficient. The relationship between disease activity with vitamin D levels in SLE patients also demonstrated in a study conducted by Tolaza which showed a negative correlation between the levels of $25(\mathrm{OH}) \mathrm{D}_{3}$ with disease activity score in SLE patients, evaluated usingby ECLAM and SLEDAI. Similar result also found in research conducted by Borba (2009). ${ }^{14}$ In Thudi, et al. (2008) study, involve 37 female SLE patients found that $20 \%$ of patients who developed clinical manifestation and immunology had lower level of $25(\mathrm{OH}) \mathrm{D}(<47.7 \mathrm{nmol} / \mathrm{L}) .^{15}$ Patients with low levels of vitamin D will significantly have higher disease activity compared to SLE patients with normal vitamin D level $(p<0.003) .{ }^{15}$ Similar results were also obtained in study conducted by Petri, et al (2013), who stated that an increased of $20 \mathrm{ng} / \mathrm{ml} 25(\mathrm{OH}) \mathrm{D}$ level would decreased disease activity in $21 \%$ patients with high disease activity score. ${ }^{13}$

Low level of vitamin $\mathrm{D}$ is one of the indicator of the ongoing inflammatory process. Inflammation potentially increases the 
metabolism of vitamin D. This suggests that patients with high SLEDAI scores may get some benefits from vitamin D supplementation. Moreover, supplementing vitamin D can improve immunological abnormalities of patients with SLE, and automatically will improve the clinical manifestations of SLE. ${ }^{10}$ The symptoms of vitamin D deficiency is still unclear. But some symptoms may arise as a result of vitamin D deficiency include: fatigue, musculoskeletal disorders (such as muscle pain found in the entire body, muscle stiffness), joint pain, weight gain, high blood pressure, sleep disturbances, impaired concentration , headache, constipation or diarrhea. ${ }^{17}$ This study showed before getting any treatment most of subjects experienced severe fatigue conditions with mean FSS score more than 4. After getting 3 months treatment, there was a significant decreased of FSS scores in the supplementation group (compared placebo group) which mean as an improvement of the fatigue condition of the patient.One study reported that nearly $81 \%$ of SLE patients experienced fatigue ${ }^{6}$, and showed an inverse relationship between level of vitamin D with the degree of fatigue on SLE patient. It is also supported by the results study conducted by Irastorza where the improvement level of vitamin D through supplementation $1,25(\mathrm{OH})_{2} \mathrm{D}_{3}$ also improved the condition of fatigue in SLE patients. $^{7}$

In a review article that included 22 studies with a total sample of 3670 patients with musculoskeletal pain and fatigue, stated that $48 \%$ of them had a significant vitamin D deficiency, and after improvement of vitamin D levels, subjects experienced some improvement in the degree of pain and muscle weakness, as well as in physical function. ${ }^{18}$ Muscle weakness has long been associated with vitamin D deficiency. This happened because there is a vitamin D receptor in skeletal muscle. Hypovitaminosis Dhas been associated with proximal muscle weakness, decreased body stability, and increased risk of falling. ${ }^{12}$ Treatment with vitamin D improves muscle function among patients with hypovitaminosis by increasing cross-sectional area of fast-twitch type II A fibers and increase muscle strength of proximal muscle. ${ }^{19}$

Fatigue severity scale (FSS) has been recommended by ACR 2007 at the Ad Hoc Committee on Systemic Lupus Erythematosus response criteria for fatigue to assess the fatigue condition in SLE patients with highvalidity and reliability. FSS has been translated into several languages. ${ }^{20}$ The FSS consists of nine questions with a range of values between 1 and 7 on each item question, with score $>4$ shows a severe condition of fatigue. ${ }^{20}$ Nine items from FSS question refers to a variety of conditions that occur in patients who experienced SLE fatigue. These conditions include: physical functioning, vitality, emotional, social, and metal health. ${ }^{21}$

In this study we found that vitamin D supplementation improved the overall FSS conditions, such as the physical functioning, vitality, emotional, social, and mental health, which indicates the presence of significant changes $(p<0.05)$ at 9 item questions in FSS.This condition is consistent with the results from research conducted by Lorentzen (2014) who found SLE patients with fatigue will cause a decrease in physical, social and mental function. ${ }^{22}$
This study also showed there was a significant association between disease activity and fatigue. Previous studies reported that SLE patient with severe fatigue had higher disease score activity. However, the main clinical features of higher disease activity is not the fatique, but the significant decreased of physical distress (headache, anxiety, musculosceletal disorder, stomachache, fever, and weight loss). ${ }^{23}$ Therefore, the relationship between fatigue and disease activity SLE is still controversial. There are some inconsistent results of the fatigue relation with SLE disease activity in previous studies. Antoni, et al.(2007) metaanalysis study, identified 34 studies published in the last 40 years. From the studies, there were 10 studies that evaluated the correlation between disease activity and fatigue in SLE patients. The 8 studies showed a significant relationship between disease activity with fatigue condition in SLE patients, but the other two did not. ${ }^{6,24-30}$ Different results obtained from Wang, et al.(1998), which found no relationship between disease activity with fatigue. ${ }^{31}$

In this study, there was no adverse effects found in the supplemented group. According to the European Commission's Scientific Committee on Food (SFC), tolerable upper intake levels (UL) of vitamin D is $50 \mathrm{mcg}$ /day equivalent to 2000 IU of vitamin $\mathrm{D}_{3}$, while the United Kingdom Expert Group on Vitamins and minerals (EVM) set a dose of $25 \mathrm{mg} /$ day. Maximum NOAEL (no observed adverse effect levels) of vitamin D is $250 \mathrm{mcg} /$ day with toxicity effects may include hypercalcemia, hypertension, nausea, vomiting and even could interfere renal function. ${ }^{32}$ Other literature mentioned that toxicity will occur if the patient is taking more than10,000 IU of vitamin D per day for months to years. Until now there is no literature available explaining the toxicity of cholecalciferol consumption less than 10,000 IU per day. ${ }^{9}$ Toxicity that occurs as a result of the increase in calcium levels are considered as secondary toxicity. This toxicity occurs gradually until levels of $25(\mathrm{OH}) \mathrm{D}$ exceeds $150 \mathrm{ng} / \mathrm{ml} .{ }^{32}$

In this research we evaluated the calcium levels both pre- and post-treatment in the supplementation group and the placebo group, at the end calcium results were within normal range.

\section{Conclusion}

The supplementation of vitamin D 1200 IU per day in SLE patients improved disease activity and fatigue conditions.

\section{Research weakness}

The weaknesses of this study are the number of subjects enrolled in this study was the minimal sample required and we did not use a double blind study.

\section{References}

1. Handono K. HLA kelas II dan kerentanan genetic terhadap lupus eritematosus sistemik di Indonesia. Acta Med Ind. 2000; 32: 11-15.

2. Costendaber KH, Feskanich D, Holmes M, Karlson EW, Benito-Garcia E. Vitamin D intake and risk of systemic lupus erythematosus and rheumatoid arthritis in women. Ann Rheum Dis 2008; 67(4):530-535.

3. Chen S, Sims GP, Chen XX, Gu YY, Chen S, Lipsky PE. Modulatory effects of 1,25-dihydroxyvitamin D 3 on human B cell differentiation. J Immunol. 2007 Aug 1;179(3):1634-1647. 
4. Leni P. Korelasi kadar vitamin D serum dengan aktifitas penyakit lupus eritematosus sistemik (Final Scription;Unpublished). 2012.

5. Irastorza GR, Egurbide MV, Olivares N, Martinez-Berriotxoa A, Aguirre C. Vitamin D deficiency in systemic lupus erythematosus: prevalence, predictors and clinical consequences. Rheumatology. 2008; 47: 920-923.

6. Tench CM, McCurdie I, White PD, D'Cruz DP.The prevalence and associations of fatique in SLE. Rheumatology (Oxford). 2000; 39(11): 1249-1254.

7. Ruiz-Irastorza G, Gordo S, Olivares N, Egurbide MV, Aguirre C. Change vitamin $\mathrm{D}$ level in patient with systemic lupus erytematosus: effect on fatique, disease activity damage. Arthritis Care Res (Hoboken). 2010 Aug; 62(8): 1160-1165.

8. SautoMID, Coelho A, Guo C, et al. Vitamin D insufficiency in Brazilian patients with SLE:prevalence, associated factors, and relationship with activity. Lupus J 2010; 20:1019-1026.

9. Cannel JJ, Hollis BW, Zasloff M, Heaney RP. Diagnosis and treatment of vitamin D deficiency. Expert Opin Pharmacother. 2008 Jan;9(1):107-118.

10. Raya AA, Helmii M, Raya SA. The Effect of Vitamin D Supplementation on Inflammatory and Hemostatic Markers and Disease Activity in Patients with Systemic Lupus Erythematosus: A Randomized Placebocontrolled Trial. J Rheumatol. 2013 Mar; 40(3):265-72. D0I: 10.3899/ jrheum.111594

11. Reinhold V. Vitamin D supplementation, 25-hydroxyvitamin D concentrations, and safety. Am J ClinNutr. 1999; 69: 842-56

12. Holic MF, Chen TC. Vitamin D deficiency: a worldwide problem with health consequences. J ClinNutr. 2008;87(suppl):S1080-1086

13. Petri M, Bello KJ, Fang $H$, Magder LS. Vitamin D in systemic lupus erythematosus modest association with disease activity and the urine protein-to-creatinine ratio. Arthitis\& Rheumatism. July 2013; 65 (7): 1865-1871

14. Borba VZC, Vieira JGH, Kasamatsu T, Radominski SC, Sato El, LazarettiCastro. Vitamin D deficiency in patients with active systemic lupus erythematosus. Osteoporosis International 2009; 20(3): 427-433.

15. Thudi A, Yin S, Wandstrat AE,et al. Vitamin D levels and disease status in Texas patients with lupus erythematosus. Am J Med Sci: 2008; 335: 99-104

16. Chapuy $M C$, Preziosi $P$, manner $M$, et al. prevalence of vitamin $D$ insufficiency in adult normal population. osteoporosint 1997;7(5):439-43

17. Gordon CM, DePeter KC, Feldman HA, Grace E, Emans SJ. Prevalence of vitamin $D$ deficiency among healthy adolosences. Arch Pediatr Adolesc Med. June 2004; 158(6):531-537.

18. Rucker D, Allan JA, Fick GH, Hanley DA. Vitamin D insufficiency in a population of healthy western Canadian. CMAJ. 2002;166(12);15171524.
19. Valebj K, Knutsen RG, Mette B, et al, Vitamin D status in patients with musculoskeletal pain, fatigue and headache: A cross-sectional descriptive study in a multi-ethnic general practice in Norway. Scandinavian Journal of Primary Health Care. 2010; 28: 166-171

20. Ad Hoc committee on systemic lupus erythematosus response criteria for fatigue. Measurement of Fatigue in Systemic Lupus Erythematosus : A Systemic Review. Arthritis \& Rheumatism. 2007: 57(8): 1348-1357

21. Neuerger GB. Measures of Fatigue. Arthritis\& Rheumatism 2003: 49(5S): 175-183.

22. Lorentzen K, Danielsen MA, Kay SD, Voss A. Validation of the fatigue severity scale in danish patients with systemic lupus erythematosus. Dan Med J. 2014;61(4):A 4808

23. Stockton KA and Kandiah. Fatigue, muscle strength and vitamin D status in women with systemic lupus erythematosus compared with healthy controls. Lupus. 2012; $21(3): 271-8$.

24. Zonana-Nacach A, Roseman JM, McGwin G, Friedman AW, Baethge BA, Reveille JD, et al. Systemic lupus erythematosus in three ethnic groups. $\mathrm{VI}$ : Factors associated with fatigue within 5 years of criteria diagnosis. Lupus. 2000; 9: 101-109

25. Tayer WG, Nicassio PM, Weisman MH, Schuman C, Daly J. Disease status predicts fatigue in systemic lupus erythematosus. J Rheumatol. 2001: 1999-2007.

26. Tench CM, Bentley D, Vleck V, McCurdie I, White P, D'CruzD.Aerobic fitness, fatigue, and physical disability in systemic lupus erythematosus. J Rheumatol. 2002; 29: 474-481.

27. Mattsson M, Moller B, Lundberg IE, Gard G, Bostrom C. Reliability and validity of the fatigue Severity Scale in Swedish for patients with systemic lupus erythematosus. Scand J Rheumatol. 2008; 37: 269-77

28. Burgos PI, Alacron GS, McGwin G, Crews K0, Reveille JD, Vila LM. Disease activity and damage are not associated with increased levels of fatigue in systemic lupus erythematosus patients from a multiethnic cohort: LXVII. Arthritis Rheum. 2009; 61: 1179-1186.

29. Da Costa D, Dritsa M, Bernatsky S, Pineau C, Ménard HA, Dasgupta K, et al. Dimensions of fatigue in systemic lupus erythematosus: Relationship to disease status and behavioral and psychosocial factors. J Rheumatol. 2006 Jul;33(7):1282-8.

30. McKinley PS, Ouellette SC, Winkel GH. The contributions of disease activity, sleep patterns, and depression to fatigue in systemic lupus erythematosus. Arthritis Rheum. 1995; 38: 826-834.

31. Wang B, Gladman DD, Urowitz MB. Fatiguein lupus is not correlated with disease activity. J Rheumatol. 1998; 25(5):892-5.

32. Hathcock JN, Andrew S, Reinhold V, Robert H. Risk assessment for vitamin D. Am J ClinNutr. 2007; 85:6-18 